\title{
Becoming smart? \\ Pursuit of sustainability in urban policy design
}

Karppi, Ilari; Vakkuri, Jarmo

\section{Introduction: In a nexus of the smart and the sustainable}

Urbanists of different generations have praised cities for their dynamism and transformational capacities (e.g. Jacobs 1961; Chakrabarti 2013). Their evolution, assisted with the available technological and managerial capacities, has been thought to make better places for the all the more urban human species. Today's leading urban development narrative is one of a smart city, even if the concept defies a single authoritative interpretation. First, the contemporary debate on the phenomenon has had several historically and geographically - or situationally peculiar points of origin (cf. Townsend 2014), even if most of its various readings seem to place at its core the amalgamation of big data and the intelligent instruments to utilize it (Ratti \& Claudel 2016, 23-24; Carpo 2017, 18). Second, and of particular interest to public management, there is an apparent tension keeping the descriptive elements of the smart city discourse apart from its clearly prescriptive ones.

This tension is caused by a prevailing dualism in the smart city discourse (Vanolo 2014, 886). While one leading concept of the smart city refers to urban development goals that can be promoted with different measures and tools, the other refers to a means of motivating diverse development projects (Rosati \& Conti 2016). Yet, regardless of whether the smart city is understood as something that can be achieved through working with identified dimensions of 'the smart' (cf. Giffinger et al. 2007) or as the setting of a developmental agenda, one thing is clear: The resolute building of a smart city requires that those in charge are willing to work with (1) the urban data and (2) the tools that make the data matter in urban governance. Both of these elements are important because the data, more abundant and cheaper than ever 
before, can now be processed in multiple and much more illustrative ways than the statistical and arithmetical methods of past data processing tools (Carpo 2017).

A key arena for using these wider data to enhance the human condition is the pursuit of greater sustainability in urban development and design. As Vanolo (2014) concluded, a great deal of the ideological underpinnings of a smart city can be traced back to smart growth and, fundamentally, the idea of cities as arenas (or 'platforms') for diverting the targeted economic growth from a respective growth in the use of natural resources (Finco \& Nijkamp 2001; cf. Owen 2010; Chakrabarti 2013). Seeking to complete this mission is nothing if not complicated. Reflecting the nature of urban areas as extremely complex systems, Beauregard (2018a, xi), in his critical account of 'the urban age', acknowledged that even if cities are the most environmentally destructive form of human settlements, they are the only settlement type to provide the scale and capacity to house the expanding global population without ecologically damaging the planet for good.

The nexus of smart and sustainable city narratives can, thus, be presented in a way such that sustainability is a fundamental goal that a smart city - or the smart use of smart tools that the smart city is assumed to compile and put in the decision makers' hands - will serve. To keep this paper compact, we have to detour the critique towards the inherent conservatism of sustainability as an ecological urban design parameter (e.g. Rottle \& Yocom 2010, 26-29). In the same vein, we need to eschew its ambiguity in the face of urban climate risks (Keenan 2014), or the fact that much of the work for making cities sustainable still stems from within traditional urban functions such as utilities (Cohen 2018). Instead, we direct our attention to the relationship between a smart system devised for sustainable urban development and design and governmentality, or the capacity to govern, dubbed by Vanolo (2014) as 'smartmentality'. 


\section{Setting the task: Smart tools in the service of public management}

This paper discusses the pursuit of urban sustainability as a public management issue. Thus, its thoroughgoing theme is the interplay between tools designed for the management use and the management processes where the tools are implemented. While our aim is to make a meaningful connection between public management and smart urban growth, we see planning as a professional practice that seeks to accommodate different organisational goals to a shared frame of pursuing sustainability targets. Overcoming the boundaries of administrative silos is hence a theme central to the paper's storyline.

We explore how cities utilize planning tools and management artefacts in their pursuits of sustainability. To assess their capacities to do so, we introduce and elaborate the concept of sustainability proxies that are necessary components for both organizing institutional complexity and for orchestrating action for enacting sustainable outcomes. Proxies, as we see them, are "hybrids in the making": shared agencies of human actors, planning tools and management artefacts that jointly comprise actor-specific interpretations (or approximations) of sustainability (Beauregard 2012; Latour 2014, 5-6). Sustainability targets become hence "proxified" according to the existing administrative divisions, or silos.

Different city contexts may facilitate different forms of proxification and thus sometimes even unexpected interpretations of sustainability targets as such. Our paper contributes to understanding on the links between planning tools and their enactment within one empirical environment. This scrutiny is followed by more general theoretical accounts of the ambiguous nature of sustainability as a target for developing smart cities. By bringing these two approaches together, we contribute to a more comprehensive understanding of 'smartness' in urban policy design and, in practice, the actual use of planning tools, management artefacts and proxies in urban policy-making. 
Traditional smart city or big data methods for dealing with urban data have commonly involved various dashboards (Mattern 2015; cf. Alfeld 1995; Medina 2006; Townsend 2014). Our approach, which prioritizes using a smart tool in a smart manner, departs from this tradition. We focus on a particular smart tool as a public managers' management artefact, not just for controlling a city's development, but for enabling urban sustainability, and, thus, explore the enactment of sustainable urban development through public management. We conceptualize this enactment as a sustainability proxy, an assemblage of sector-specific measures for promoting the equally sector-specific vision of a sustainable urban growth. Furthermore, we empirically demonstrate how smart tools may contribute to the constitution of this proxy. Proxies of any kind are rife with limitations and ambiguities, yet cities and public managers need to use them to organize the complexity that prevails around them.

The empirical focus of our study is a smart planning and policy tool developed in Tampere, a fast-growing Finnish smart city (City of Tampere 2018; Giffinger 2007, 16). The tool seeks to integrate the typically siloed planning realms of service provision, housing, traffic and land-use (PALM, described in Chapter 3), into one strategic entity. Our empirical question is: what it takes, institutionally and in terms of professional practices, to turn a piece of smart technology into a workable policy tool for promoting sustainable urban development. However, it is crucial to understand that even if we regard PALM as a tool for creating an integrated proxy for sustainable urban development, we do not assume a direct connection from the tool to this target. Such a connection is shown in Figure 1a. In a complex system, reaching this target needs to be achieved through a string of targets and due actions (Fig 1b). Furthermore, much of the process tends to be delegated to the technologies and 'things' (Beauregard 2012, 2018b) present and active in its sub-systems. In concert, they seek to attain the target or, at least, its essentials. 
******* INSERT FIGURE 1 AROUND HERE*******

Figure 1 does not portray our research setting; instead, it features a practical disposition in which an actor (city, authority, enterprise, etc.) uses a tool, presumably appropriate for reaching an indicated goal for action, in its possession. In our case, this tool is understood to be a 'smart' one, largely in line with the established smart city interpretation that emphasizes the availability of urban data and, hence, measurability of urban transformations (Ratti \& Claudel 2016). The actor uses it to reach a desired or mandated sustainability target.

Sustainability is an important yet abstract and ambiguous target to be reached with one designated tool; however, resorting to a sustainability proxy is a pragmatic means for making the target governable. Tools, in turn, generally help to contextualize this proxy and render it meaningful for different administrative environments and uses. Moreover, as PALM is tailormade for the City of Tampere, it differs from planning tools or management artefacts used in other cities. We posit that its essential trait is its kaleidoscopic nature, which helps planners and decision-makers representing different departments and offices to perceive the aspects and elements most relevant to them, nested in an integrated, cross-sectoral scenario for the next 12 years - or three city councils' terms of office. Different tools enable different enactments. Thus, distinct forms of proxification evolve through interaction between tools (e.g. PALM) and the ways in which they are implemented and enacted. What's more, the way these enactments are integrated into a meaningful whole and put into operation largely determines how well the proxy captures the complexities and ambiguities of the targeted pursuit of sustainability.

Methodologically, we utilized comprehensive, longitudinal case study data based on research work between 2015 and 2018. that addressed the ideals and complexities of pursuing sustainability in the context of Finnish urban-policy design. Our dataset comprised detailed 
documentary data on the strategies, financials, management and decision-making of Tampere. Moreover, we interviewed professionals, from the designers and operational users of the PALM to the sectoral managers, division heads and top civil servants of its design, use and role in pursuing sustainability and - eventually - 'becoming smart'. Three thematic group interviews involving 11 informants (some of whom participated in more than one interview) were conducted between the spring of 2015 and the winter of 2017. We started with the strategic birds-eye perspective of the PALM and, in the final interview, zoomed in on its practical design issues (cf. Appendix). The number of informants varied between three and six, and the number or interviewers between two and four. The interviews were recorded, and the recordings were turned into transcripts. The transcripts were analysed in a mixedmethods framework (Castro et al. 2010) together with documentation of the PALM, City of Tampere strategic governance and planning documentation, long-term land-use plans and sustainable development plans.

The paper proceeds as follows. Chapter 3 is based on our empirical study of the pursuit of sustainability in a growing city by utilizing a smart tool, the PALM. By focussing on it, we illuminate two perspectives on how the promotion of sustainability in an urban setting can be seen. We first discuss the sector and activity-specific smart components of urban development and an integrative view of them, dubbed as a kaleidoscopic approach to smart components. Next, we ask if PALM, the provider of the particular kaleidoscopic view, ultimately has the capacity to overcome the sector-emphasizing logic never far away from public management. We continue, in Chapter 4, by asking if sustainability can be planned and then elaborating the more detailed idea of proxies through which the pursuit of sustainable urban development - as an administrative necessity - takes place. Through this process, the proxies become visible. Chapter 5 concludes the article-long span of constructing an argument on smart urbanity as a distinctive vehicle for promoting sustainable development 
that should take place as and interplay between administrative silos. This also highlights our conviction that smart urbanity needs to go beyond the technology push persistent in the customary smart city thinking all around the world and be embedded in the (public) management of urban transformations.

\section{From smart cities to smart urbanism to smart sustainability}

So far, we have taken nearly for granted that there is a kind of smart urbanism that transcends the elements customarily understood as essential for smart cities and, therefore, requires integrative tools and artefacts. The demand for an integrative approach with new knowledge bases, tools and co-operative practices is a theme that now pops up regularly. McPhearson et al. (2016) went so far as to call it an emerging 'science of cities'. In this empirically weighted chapter, we put these concepts in an operational order, embedding them in a real-world context of a growing city of Tampere.

\subsection{Making proxies tangible for the management of public resources: PALM}

The PALM is a tool for the long-term programming of land use and investments of the City of Tampere and its various real-estate and utility companies. The current PALM programming period comprises the years 2015-2029. It is based on the structural plan of the Tampere City Region, a programme for housing 115,000 new residents of the city region by the year 2040, with a projected population of 480,000 . Next, we briefly describe the sociodemographic environment where the PALM is applied.

Tampere, the urban core of Finland's second city region, has a population of 235,000, and its long-term estimated growth is 2,000 new residents annually. The actual increase currently 
exceeds this estimate significantly, with the average annual growth between the years 2011 and 2017 being almost 2,700. In 2017, a year of record growth, the figure exceeded 3,700. With such growth, the city inevitably needs to solve multiple but siloed problems of land use, service provision and traffic, all of them entailing investments, in a sustainable manner both in terms of financial and ecological sustainability. Growth in itself is a positive 'problem'. Finland is a prime example of ageing industrial nations with stagnating population growth. While a handful of Finnish city regions are growing, the great majority of rural areas and smaller peripheral and now even mid-size university towns are shrinking in population. Instead of mere migration, it is possible to speak of a progressing population relocation, which makes it increasingly difficult to predict the angle of population growth in the most attractive cities and city regions, particularly in Tampere, Finland's second city.

The PALM is part of the city's financial and strategy process, updated annually in tandem with the city's town-planning/land-use programme. The land-use implementation programme is regarded as one parameter of investment planning, together with overall financial condition and population growth estimates. Thus, the tool essentially requires an interplay across sector boundaries. This versatility is well visible in the fact that the PALM 2015-2029 went through seven distinct stages of both sector-specific and general decision-making, including the mayor's management team and the politically influential city executive board's planning meeting, before reaching the urban development board responsible for sustainable urban land use development. The PALM projects the availability of urban land for residential and business uses from 2015 until the target year (the beginning of 2030) and includes all the planned investments of the city between 2015 and 2029, including its own business entities and important subsidiary companies. It treats all forms of acquisitions (e.g. leasing) as investments and considers the sufficiency of the estimated cash flows and financing, including income from property development and sales of fixed capital assets. 
The explicit principles for programming investments are to enable the city's future growth and to enhance the functionality of the existing structures and installations. Some large-scale individual development processes, such as the light-rail transit system (in construction since 2017), are included in the PALM, as are the construction programmes for the city region's school network and water and wastewater utilities, all in response to the rapidly growing demand for more capacity.

\subsection{In a kaleidoscopic world of the PALM: Components of a smart city}

We start by looking at the more strategic perspective that underlies (1) the methods for pursuing sustainability in general and (2) the PALM in particular as a tool used in this pursuit. However, given the strongly compartmentalized nature of pursuing sustainable outcomes, we start with some characteristics of the frictions within integrative systems, frictions that show what kind of (often inherited or even structurally sedimented) obstacles the organizational division of labour may hide or even be based upon.

A growing criticism towards the contemporary smart city discourse focusses on the concept's inadequateness for reaching the experiential aspects of urban living (McFarlane \& Söderström 2017; Townsend 2014; Ratti \& Claudel 2016). As cities are made for and with people, it is obvious that smart tools have a long way to go to reach many of the key sustainability goals, those of liveable (urban) environments and cityscapes. The leading civil servants we interviewed in Tampere in 2015 emphasized the experiential aspect - not as lip service to the official public participation credo but as a way of gaining valuable information for better planning and use of public resources. Also, architects and other urban-design professionals have become aware of the limits set by their professional silos (cf. Steiner 2011; Beauregard 2012). For example, they are increasingly taking heed of what has happened in the overall socio-technological reorganization of global material assemblages 
(Carpo 2017; Lieto 2017). These transformations have become inseparable parts of our daily lives, which motivated Lyster (2016) to trace new urban planning principles based on them. Urbanism-on-demand, the idea of a future city as an integrated platform, can be an ideal that utilizes our knowledge of anything online, extending it far beyond commercial uses and putting individual urban dwellers at its core (cf. Townsend 2014).

But this is only one aspect of planning, and more needs to take place in the way of integration before 'smart urbanism-on-demand' can be possible. Here, the PALM as a tool provides a kaleidoscopic view of the city and its spatial development. It collects the key bits and pieces of urban development, both spatially (city district by city district) and as an interplay of functional sectors and corporate entities under the influence of city hall. Moreover, in principle, it provides a long-term timescale with city-district-level population projections as its backbone. However, the kaleidoscope is rotated regularly, with annual budgets plus the next three years' preparedness and land reservations for large construction projects reorganizing the view. Our informants agreed that this feature makes it emphatically a tool that best serves looking at urban development from above, from the vantage point of centrally administered strategy and budgetary processes, with senior civil servants' and key elected policymakers' participation in parallel management teams diverting the view from the pursuit of sustainability in the narrow divisional confines of sector-specific logic.

Consequently, our top civil-servant informants claimed that the PALM is a tool for constructing a vision, not a plan. But it also works as a planning tool of sorts, provided that the scale of planning goals is large enough. An example of a plan that matches this criterion is Finland's longest road tunnel (2.3 km, opened in 2016), which cleared new land for residential construction and more general infill of urban structures, extending Tampere's city centre to a valuable lakeshore area. The $300+$ M€ light-rail project, now under construction, 
is another. These are strategic megaprojects (cf. Flyvbjerg et al. 2003) that the PALM helps to separate from the regular financial cycles in which they would be restricted by the more short-term, even annual budgetary regimen that the City of Tampere otherwise follows. Processes of related scale and strategic scope are in the pipeline, some of which have already moved to the implementation stage since the interviews.

But do these accomplishments really require a tool proclaimed as a smart city development device? This, naturally, is a polite way of asking what makes the PALM so smart in the first place. It does have its technical sophistication, but, much more than that, we claim, its actual effective smartness (or the lack of it) stems from its use, smart or not, and not from its affordance to those in charge of sustainable urban development. Instead, the PALM has been developed alongside the 'designated Smart Tampere' framework, from a set of practical management needs up. This pinpoints the PALM's inherently strategic, bird's eye view to the city, as well as what it takes to use its administrative apparatus in order to plan, design and manage its urban area in a sustainable manner. Somewhat disturbingly, it also suggests that developing a smart city may be another sector-defined activity, promoted through highly specific interests (cf. McFarlane \& Söderström 2017; Rosati \& Conti 2016) and confined by the boundaries its own administrative silo.

A PALM system developer captured the problem of the system's standing in an intersection of different interests and requirements in addition to the fact that it has to face myriad problems stemming from the insufficient communication across the borders of the siloed activities:

It's like a game of Tetris in the urban fabric. We should be able to control the volumes of planning and investments but also [...] show the causalities. If we reschedule the 
building of a school or an entire district, where does it lead to, how is it connected [to tasks of other offices]?

Despite their strategic position to envision, monitor and, as we saw, 'plan' city development from above, the top civil servants we interviewed were forced to concede the sectors' and silos' power in more detailed decision-making. A phrase often heard in the interviews referred to things that are inside the PALM displays showing the intensity of investments and construction in various city districts over time. These 'things' consist of specific services, such as children's day care, or systemic transformations, including changes in service production models introduced through new institutional innovations like the emergence of hybrid governance (cf. Johanson \& Vakkuri 2017). Here, the long-term logic that structurally unites land-use planning and strategic investments must give way to service demands that follow from changes in housing or residential preferences. In the 2010s, this happened as a response to - or a distant ripple effect of - the 2008 Wall Street financial crisis. This also adds a layer to the complexity of pursuing smart sustainability in urban development with the help of a smart tool, however comprehensive, that basically operates with all of the spatial body-parts of an entire city.

\subsection{How does PALM relate with the smart urban sustainability debate?}

Instead of being containers that should hold in human populations with their material and immaterial possessions, cities are parts of a global urban network that is in constant flux and constitutes the principal mechanism that distributes humankind over the Earth's surface. Ecosystems and the environmental impacts of human action do not conform to the boundaries of governmental jurisdiction, whether it be local, regional or national. Often, no single administrative-governmental level possesses the authority or means to address a particular environmental problem or to achieve overall sustainability (Portney 2013). This raises the 
question of whether finding smart but often situational solutions for achieving sustainability is even feasible. Yet, there are strong practical arguments that favour choosing cities and their planning tasks as units of sustainability analysis and action. They constitute a platform for some of the most innovative solutions for smart systems (Ratti \& Belleri 2017).

First, urbanization and the increase in wealth that is associated with it are the main drivers of current local and global environmental degradation (Hoornweg et al. 2011). These adverse environmental consequences of urban growth include the pollution of air, water and soil, the degradation of natural habitats, biodiversity loss and unsustainable consumption patterns, all epitomized by urban sprawl, the (uncontrolled) low-density expansion of cities and their suburbs to 'nature' (Gardner, Prugh \& Renner 2016; McPhearson et al. 2016; Rottle \& Yocom 2010; Stern 2010). Hence, the needed solutions are global in their reach, but - as efficient policy measures and public-management issues - they need to be found in individual cities, and this is what the PALM, with its key policy areas, set out to accomplish in Tampere.

In addition to environmental degradation, urban growth may have adverse social consequences. The benefits of urbanization are seldom reaped equally (Beauregard 2018a), and urban-growth dynamisms may entail a privatization of benefits and a socialization of costs. This is one of the 'things' in the inner workings of the PALM we referred to above. It is not visible in the system's investment/land-use logic but potentially becomes palpable in reforms in diverse service-providing sectors. Other negative externalities of urbanization, such as time and productivity losses due to long commuting distances and congestion, health problems caused by pollution and vulnerability to extreme climatic conditions such as flooding and sea-level rise, may end up being borne by less-favoured groups (climate gentrification). Therefore, knowing where and how to invest in making new urban space is a 
vital element of sustainable urbanism. Moreover, cities, as accumulations of material and immaterial resources, often dubbed generators of innovation and creativity, should be both best equipped and most motivated to find solutions to problems of this magnitude. Tools such as the PALM must combine the 'production' of urban density appreciated by the innovative industries (Katz \& Wagner 2014) with aspects of social sustainability, such as affordable housing and public transit (Center for Transit-Oriented Development 2009).

Second, cities have the legitimacy and authority to address issues within their borders, even if this is not the optimal scope for addressing a specific environmental concern. This is particularly true in Finland, with its long and constitutionally guaranteed tradition of municipal self-government. Cities can actively use policy tools that affect lifestyle choices and, thus, decrease energy demand and per-capita greenhouse gas emissions. They range from mixed-use zoning to improving the quality and availability of public transit, encouraging cycling and walking, enacting restrictive parking policies, promoting transitoriented urban development and enhancing energy efficiency in buildings (Hoornweg et al. 2011; Renne 2009).

Most of these measures come from a 'legacy urbanist' portfolio and are strongly present in the land-use/investment logic of the PALM. Understanding these as strategic decisionmaking artefacts, kaleidoscopic systems such as the PALM can express an institutional demand for what can be achieved with regular smart city tools that focus on sensor data and measurable flows and that can further fine tune necessary sustainability measures. What the tools cannot do is to take away these measures' inbuilt trait of necessarily 'proxifying' the sustainable urbanity the city seeks to promote.

It is no accident that proxies have such a prominent role in turning sustainability targets into material facts. Cities inherently tend to be pragmatic. While planning for a long range, they 
routinely tackle everyday problems relating to various forms of sustainability as a key feature of commutable, healthy, cost-efficient and safe environments for work and living (Hoornweg 2016). Conversely, the more abstract political will or mutual understanding on how to address sustainability concerns cannot be constantly present in their governance (Portney 2013). Blanco and Mazmanian (2014) and Hoornweg (2016) share this practical approach. For them, cities constitute critical building blocks of a more sustainable future since global action, although necessary, is still far from being a politically viable option. Instead, Blanco and Mazmanian (2014) also pointed out, cities make it possible to experiment with how sustainability outcomes can be achieved in diverse local conditions. Many cities have indeed taken active roles in climate-change action and the promotion of sustainable development, independent of the attitudes of their national governments towards environmental matters. The US under the Trump administration provides a convincing case in point.

\subsection{Finally: does PALM really matter?}

We also interviewed two groups of professionals in managerial or specialist positions a step or two below the highest-ranking city officials, whose interpretations of the PALM prompted us to describe it as a kaleidoscopic instrument. Our assumptions of the administrative sectors' dominance in the practical uses of the PALM - despite all the good intentions of developing an integrated view of sustainable urban development with it - only grew stronger after these interviews. Among these informants was a civil servant who had a key role in designing and further developing the PALM, as well as senior managers who represented the 'things' inside the PALM (see above). The kaleidoscopic character of the PALM was excellently highlighted by a comment on its basic problems, both atomistic and, for want of a better expression, institutional. These included insufficient data coverage on vital aspects of 
sustainability, the splintered data serving as an apt metaphorical equivalent of the pieces of glass in a kaleidoscope rotated over-and-over-again in search of the perfect pattern.

But this was a mere technicality. The more profound problem, the interviewees noted, concerned ownership. It being common knowledge that the PALM played a part in a strategy process, diverse city offices were interested in using it or being included in it - and receiving a broader approval to their sector-specific goals. That there was not such a straightforward relationship between city strategy and the PALM became clear in the interviews with senior management. Simultaneously, a problem emerged from the fact that, even if a broad range of city offices felt like owning at least some part of the PALM, none of them thought of it as their institutional possession. Therefore, despite the coherent view the PALM provides on sustainable urban development, at least some offices reflected their investment plans through it, believing that they would be in line with the more strategic view the PALM was seen to convey and that they would therefore fit into the city's financial frame. Whether it was the PALM's underlying investment logic or not, the way urban development was seen to flow through it was easily interpreted as a manifestation of the city's fixed assets and matter. To sum it up, a well-versed service developer in a managerial position said, 'Land use lays the foundations, we [services] try to muddle through in its wake'.

So, does the PALM - itself an obvious proxy for a smart tool - matter? Based on the interviews, it does, but not necessarily as a coherent artefact for producing smart and sustainable urbanity. It is an important tool for those who can transcend the sector-specific logic that, after all, follows from the city administration's attempts to organize complexity through the division of labour. All the interviewees, regardless of their administrative position, agreed that, should the PALM not exist, some other tool to capture the diverse perspectives on urban development would be needed and designed. However, its sector- 
transcending position makes it politically vulnerable. If elections dramatically redistribute city council seats, the new council may be tempted to put former decisions aside and start afresh. In such instances, Leitmotifs that transcend the lifespans of elected government bodies, such as promoting sustainable development in lieu of pursuing the 2015 Paris climate targets with PALM-like systems, must be underscored. In the words of a system developer:

$\underline{\text { PALM has a dual role. Some people see it as a governance instrument and, in a way, a }}$ planning tool. Others need a paper for political [budgetary] decisions once a year [...]. They regard it as a pile of paper, not a tool at all.

A collision between the tool and policy features in a PALM-like, clearly strategic smart system may even be inevitable. Unlike the regular smart tools for measurement, control and governance, it may not even be able to make a difference unless it is exposed to the logic of fundamentally political decisions on how sustainability is framed in a given urban context and how smart urbanity aims to find a trajectory that leads to that goal.

\section{Can sustainability be planned? Sustainability proxies in urban policy- making}

The pursuit of sustainability is usually compressed into generic planning guidelines. However, what planners of sustainability de facto do, as we saw with the PALM, is work with locally relevant components of sustainability that reflect the functionally structured administrative divisions of labour and are promoted with the instruments and locally de-vised instructions for their use. Moreover, this planning takes place within already institutionalized administrative divisions. All of these can be considered resources in the hands of public managers and urban planners. 


\subsection{Sustainability as a concept and a hard thing to plan}

Sustainability is a notoriously ambiguous, even treacherous concept (cf. Vakkuri 2010; Karppi \& Vakkuri 2018). Several distinct schools of thought focus on one or another of its manifestations. Sustainability is customarily divided between strong, non-anthropocentric sustainability, which recognizes natural environments' intrinsic value, and weak, anthropocentric sustainability, which considers natural environments as having instrumental value to human wellbeing (e.g., Pelenc \& Ballet 2015). Here, the urban context obviously represents an extra-weak form of sustainability. It is fundamentally an accumulation of human-made, artificial landforms, matter and things, which adds remarkable inertia to the already conservative concept. With the exceptions of natural or human-induced catastrophes, urban matter and urban tissue transform over lengthy time spans (e.g., Hamblyn 2009, 36, $60)$.

Given the absent heuristics of what is fundamentally at stake in sustainability, the smart city performance measurements and measurers widely used in public management are by nature only able to produce approximations of sustainability (cf. Keenan2014). These approximations occur in the construction and selection of planning principles and goals, such as transit-oriented development, the walkable city, carbon-footprint reduction, LEED standards, sprawl prevention or even the ubiquitous sustainable urbanism (e.g., Renne 2009; Talen 2011; Speck 2012; Duany 2013; Owen 2010). All of these are major issues of planning practice. Thus, planning as a process appears to be a key vehicle for promoting sustainability in an urban environment. But can sustainability be planned, and if attempted, will it stumble into tensions between a wide range of legitimate ideals and the limited means of turning them into workable policy practice? 
Changing climatic considerations have forced even the most diehard humanists within the planning profession to reconsider the traditional predispositions for prioritizing human needs over anything else and using them as the yardstick for sustainability (Beauregard 2015; 2018b; cf. Latour 1994). This is a necessary step, as planning's track record in producing sustainable urbanity is anything but impeccable. Departing from the early Geddesian ideal of the integrated planning of entire systemic entities that comprise cities and their hinterlands or contemporary urban regions - cities have been designed as objects teeming with engineering challenges but with scant reference to the nature in which they are located (e.g. Hajer 2014, 26; cf. Wartiainen 1995; MacKaye 1968; Mumford 1949).

For public management, things only get more complicated, as the question of financial sustainability is allowed to enter the assemblage of sustainability attributes. Local communities are meant to be fiscally self-reliant. If fiscal self-reliance is taken as a genuine goal, then various policy measures should be geared to serve it. These would include land use, urban planning, public service provision, housing, transit and business promotion, all typically cushioned, if not entirely insulated, in their own administrative silos (Vakkuri et al. 2016). Even if smart solutions might help to breach those silos, we stumble with them into pseudo-ontographic rosters of things that help us, at best, construct more (but one hopes more accurate) sustainability proxies (cf. Beauregard 2012). A smart tool might be of use here, but, we argue, only if used in a smart manner, as an emergent socio-technical practice (Meijer \& Bolivar 2016, 403-404; Mergel 2018).

While these components may be approached with planning practices - treating them as isolated or siloed incidents - this may not be the case with the entire sustainability assemblage. Due to its context and actor specificity, its ontographic qualities are undeniable, but, as Beauregard (2015) noted, planning is not ontographic. It cherishes a fundamentally 
rational worldview, however rough or even deluded its approximation of the workings of planning scenes, where sustainability in all its fluidity and repleteness is pursued. Thus, even in the realm of ideas untouched by the complexities of the material world, with its situationality and conceptual ambiguity, it is highly questionable whether sustainability can be planned at all. A great deal of prior experience suggests that this is so. Sustainable urbanism and how to achieve it have been the cause of an exceptionally bitter twenty-firstcentury rivalry between different urban design communities (Duany \& Talen 2013), even if sustainable development has been a 'master concept' legitimating national and local planning apparatuses' resistance to the market-led tide that has prevailed for over three decades (cf. Meadowcroft 1999; 2007).

The more vital question is perhaps one that explores the processes and methods of planning and measurement by which cities pursue the more intelligible design and utilization of diverse sustainability proxies. Reaching sustainability is an ambiguous policy goal, and the complexity faced by organizations and administrations, by definition, cannot be tackled with linear, one-dimensional or simply measurable action. The smart city holds a promise of better tools to 'feel the pulse' of urban development and lived urbanity, to identify, combine and illustrate elements and embryonic trends in development that would otherwise go unnoticed (Nam \& Pardo 2011; Ratti \& Claudel 2016). However, it is far from certain that these tools can be used in a way that fully exploits their splendidly holistic variety (Sterling 2018).

\subsection{Sustainability proxies that we live by}

As measurement, validation and the provision of evidence are what administrations and public managers are required to provide, we easily content ourselves with producing evidence that operating with proxies 'brings about' the expected results (cf. Vosselman 2014). Attempts to produce smart and sustainable urbanity is no exception but, rather, a reflection of 
how we 'act with things' (Beauregard 2015). Phenomenologically established, institutionally embedded and frequently encountered, proxies are entities that we literally live by while seeing sustainability targets through them. In many accounts, pursuing urban sustainability is not merely about performance but also has to do with performativity, whereby proxies-asartefacts enable ideas of sustainability turned into action with material consequences. These actions, or acts of urban policy-making, are justified and legitimated through various forms of performance metrics and calculated orders that reveal what we hope the proxies to be (cf. Revellino \& Mouritzen 2015; Johanson \& Vakkuri 2017).

To analyse how well these proxies jointly match the sustainability goal that is both normative and deliberatively set, we focused on the City of Tampere. Its uses of the PALM seek not only to allow land-use planners to bridle further sprawling of the urban space but to do it with an eye on financial sustainability, specifically, a long-term perspective on investments and public service provision. All of these are vital aspects of the urbanization of a fast-growing city. The PALM is designed to bring all of the abovementioned aspects of promoting sustainability within one management frame. Yet, given the complexities of sustainability as a policy and planning target, as it was seen in Chapter 3 above, it succeeds to cover the city's sustainability goal only partially. It seeks to transcend the limits of actor- and division-based, or siloed, proxies for sustainability and hence provide a holistic image of the target. However, as it was seen, the silos are obdurate: they struggle to bring back the proxies with their limitations. Figure 2 shows a graphical expression of the unfolding of the problem in a general form.

It starts with the setting of an original sustainability target (step A) with all its inherent ambiguities, as discussed above. An example of such targets - binding, yet vaguely set - is the $40 \%$ greenhouse gas reduction as stipulated in the intended Nationally Determined 
Contribution (NDCs) of the EU and its member states. Together with contributions determined by other nations, they comprise the core of the 2015 Paris Agreement to limit the global temperature increase to 1.5 centigrade above pre-industrial levels. The target is exactly set from the viewpoint of one dimension of sustainability, but the means of reaching it remain open. In its intended NDC, the EU, Finland included (Submission 2015), committed itself to at least a $40 \%$ domestic reduction of greenhouse gas by 2030 . However, it does not recognize urbanization as a frame for achieving the reduction target, regardless of Europe being a predominantly urban continent and the growth of urban areas being a key feature in its territorial development. Thus, the processes of reaching the binding sustainability targets in largely urban environments need to be found in cities, case by case, or through learning from each other (Stern 2010).

\section{*******INSERT FIGURE 2 AROUND HERE*******}

Here, the administratively distributed capacity to govern complex developments steps in. Figure 2 conceptualizes how the original target of promoting sustainable, pro-NDC (urban) development mutates into an unrecognizable form (steps B to C) when the siloed proxies for piecemeal sustainability targets come together with the city offices seeking to tackle the task set to them. They comprise some but not nearly all aspects of the complex phenomenon. One can easily perceive the overlaps and inconsistencies that emerge when the original target is 'compartmentalized' with the tools and aspirations vested in the institutional machinery inherent in the divisions within any large organization. Such task-based divisions are there to enable the efficient use of functionally distributed and diversified skills and other resources. Reaching smartness, sustainability or other broad, cross-sectoral goals requires the concerted use of these resources. 
The pooling of resources is accompanied by the constellations of diverse approaches to and interpretations of the shared endeavour. For example, even if financial sustainability is an aspect of the original sustainability target, it becomes essentially - and necessarily - turned towards other measures than, say, protecting biodiversity within the urban setting. It is simultaneously an important part of a sustainable urban-development assemblage and a part of the assemblage with highly specific conceptual and factual attachments. Consequently, two different kinds of metrics and smart tools to process them are simultaneously at play. The kaleidoscope rotates.

We argue that these complications, visible in step D, between a virtually ubiquitous, allencompassing or society-wide sustainability target and sector-specific responses (from planning and implementation to measurement and validation of the measures) to promote sustainability must be acknowledged and even highlighted on a regular basis. It is particularly important to do so whenever any transformational dynamic reaches the magnitude of a driver for societal development. Until now, the technological basis for designing smart cities has been a kind of 'superdriver' (Brynjolfsson \& McAfee 2016), but it is only one of the concurrent elements justifying the wake-up call. Societies face an amalgamated problem in pursuing sustainability in an urban setting in which continuous urbanization needs to be managed in an environment marked by ageing populations, depleting natural resources and oscillatory weather (Karppi \& Vakkuri 2019). All of these can be turned into something that requires a response with major implications for financial sustainability and/or public management.

The technology-push legacy of smart cities represents a particular promise, as it has done for the past half century, starting with the urban-dynamics solutions of the late 1960s (e.g. Forrester 1970; Kadanoff 1971; cf. Alfeld 1995; Townsend 2014; Graeber 2015; McFarlane 
\& Söderström 2017). From these early years on, the idea of a smart city has coexisted with new tools and elements for planning, for gathering and analysing more information and for turning the idea into a more detailed knowledge of the state of the urban space. That this knowledge is created though tapping into traffic, energy or other easily measurable data on vital urban flows has long been a sheer necessity. As the principal workings of availability heuristics suggest, one adjusts one's ideas of how to construct an image of reality to the supply of information at hand. Based on the above discussion of sustainability proxies, it is easy to claim that the thing created by so doing is, at best, far from a 'complete proxy' for awareness of the necessary plans and ways of execution for living more sustainably in urban settings (cf. Chakrabarti 2013; Owen 2010; Speck 2012). The mechanism through which such proxies, with all their limitations and shortcomings, are actually transformed into legitimate urban policy actions is extremely interesting.

\subsection{Performance management and sustainable urban development}

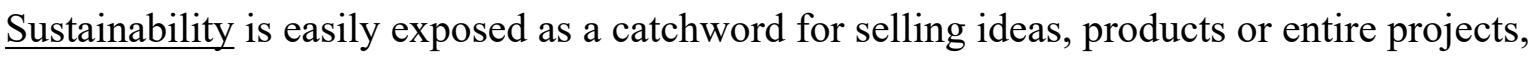
but, as Zeemering (2018) noted, in public management, it also appears as a reform concept. However, its prominent role in various policy formulations only increases the concept's complexity. Moreover, contrasted with kindred design epithets in environmental planning, such as 'resilient-' or 'regenerative', sustainability is easily portrayed as emphatically conservative, focussing on contemporary conditions, resources and even values (Rottle \& Yocom 2010, 76-78; cf. Berke 2002). This inherent conservatism can be discerned even in the infamous rivalries between landscape and new urbanists, both of whom are self-appointed vanguards and protectors of sustainability (with their own interests and emphases) in the expanding urban world (Steiner 2011; Sorkin 2013). The conservative spin can also be seen 
in the idea of smart growth, which transcends the limitations set by the spatial scale of individual project sites or places in the urban tissue.

Cities, the suburban areas that surround them and the entire scales of urbanization are in a constant flux. The transformations in inward- and outward-bound growth in urban areas have been one of the constant features in urbanization. Traditionally, urban growth or shrinkage has had clear, often culturally recognizable patterns. Anti-urbanism, embedded in many Hollywood productions in the late 1940s, and the later back-to-nature movement have both bred counter-urbanization sentiment, albeit with different manifestations and consequences for settlement structures (cf. Chakrabarti 2013, 36-39). The pronounced cosmopolitan lifestyles of the 1980s and the associated lure of great cities were particularly fuelled by the decade's financial liberalization. In the current situation, we find it particularly apt to approach urbanization as a public management issue in which urban planning and decisionmaking practices merge (cf. van Dorp 2018, 1240). It provides the context within which sustainability outcomes are pursued and assessed and where sustainability assessments become important to decision-makers aiming to legitimize their actions to relevant stakeholders and society in general. The term urban development is used here to encompass the practices of both urban planning and decision-making, and the familiar approaches within the framework of performance management are used to analyse and assess urban development outcomes.

While the performance measurement and evaluation objective is to support public decisionmaking with timely, correct and effective information and knowledge (van Dooren et al. 2015), the triad of sustainability, urban development and performance management comprises the key points of smartness in an urban context. Therefore, it is essential to understand the basic assumptions upon which indicators and smart tools are built (Vakkuri 
2010). Regarding the scope of this paper, it is important to understand the potentials and limitations of the indicators, both as parts of the inner workings of the proxies and as sources of information against which their legitimation as sustainability proxies is assessed. Without discussing what sustainability as a dimension of smart urban development entails - or could entail - it is impossible to understand what is actually measured in an attempted measurement of urban sustainability or to comprehend the limitations of any given set of sustainability indicators.

\section{Discussion and conclusions}

Sustainability is a multidimensional concept that, due to its repleteness, constitutes an extremely complicated field for public management. Promoting sustainability in urban development is about promoting not only ecological but also social and economic/financial sustainability. The overarching or legally binding requirements for cities to set sustainability targets stems from the Nationally Determined Contributions to the Paris Agreement. Cities are supposed to reach these targets without risking the social aspects of sustainability or their financial health. Strong growth in successful city regions brings in the risk of advancing urban sprawl, an imminent threat to the different aspects of sustainability.

Turning quantitatively measured growth into smart growth may remarkably benefit from the use of smart tools (Vanolo 2014). We asked how such a process would look from the perspective of a tool and its actual use. We also had to ask if it is possible to 'plan' sustainability. That is a question that largely transcends this paper, being a truly fundamental puzzle in regard to the relationship between (1) humans as the perceived subjects, actors and 
decision-makers in the planning process and (2) the environment - in its different forms - as the perceived object of urban planning and public management.

This idea of the controllability of the environment conforms with traditional ideals of planning with clear distinctions and boundaries that separate humans from both nature and technologies (Beauregard 2018b; cf. Latour 1984). This is a worldview that appears deceptively simple, persuasive and, in some regards, perfectly aligned with the Zeitgeist of the current managerial apparatus. Roles, responsibilities and points of performance measurement are easy to identify and establish on the basis of these distinctions, which themselves become management artefacts.

The globally amalgamated demographic, climatic and other changes have put cities in the ultimate position of not only facing the sustainability challenge but also finding ways to act accordingly. Urbanization as a global phenomenon is a touchstone for sustainability, while sustainable urban development is a process that requires new kind of knowledge, analytical power and novel forms of governance (Castelnovo \& Sorrentino 2018; McPhearson et al. 2016; cf. Hajer \& Dassen 2014; Johanson \& Vakkuri 2017). However, despite this global

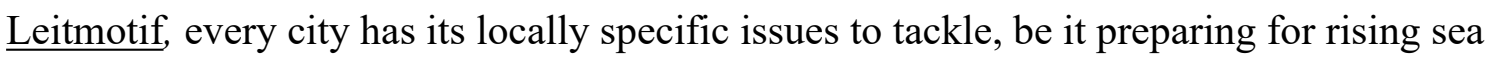
levels (Keenan 2014), housing new residents en masse through densified urban structures (Keenan \& Chakrabarti 2013), reurbanizing large old housing estates/projects (Paans \& Pasel 2014) or dealing with the repercussions of global tax competition on affordable housing regimes (Rumpfhuber et al. 2012).

This paper has taken an empirical look at one city and its attempt to promote sustainable urban development with a specific planning and management tool. The PALM can easily be understood as an example of the long tradition of smart tools designed for working with urban data, something that subscribes to the clear distinctions and boundaries between 
different domains of urban knowledge. However, even if the artefact helps to construct a holistic, multi-annual perspective of urban development and the financials that it requires, the kaleidoscopic view, as we called it, easily splinters into roles, responsibilities and performance targets of administrative sectors. You divide your world into separate boxes, and an assemblage of divided proxies shaped by these boxes is what you receive.

We discussed the impacts of this boxifying through sustainability proxies as an example that turns the holistic, far-reaching and sometimes even theoretically motivated policy goals into tangible managerial action with material consequences. Even if it were fashionable to use all the shortcomings in the actual attainment of holistic sustainability goals as further evidence to demand the breakup of administrative silos, we see them as unavoidable instruments for organizing the complexities that public management and public managers necessarily encounter. A great deal of institutional naïveté would be required to not recognize the rational reasons for that kind of specialization among public managers and urban planners alike.

However, the limitations set by the sectoral boundaries need to be acknowledged and acted upon accordingly. We have labelled the two ways of looking at this as (1) the smart city perspective and (2) the smart urbanity perspective to sustainability proxies. The traditional smart city approach would emphasize processes of making the components that constitute the proxy for reaching sustainability targets as smart as possible. This would be done with the use of all available forms of data. The problem with this approach is that it would obviously further cement the silos, as the ever-perfected understanding of sector-specific issues could make it more difficult to connect them with the worldviews created in other silos.

The smart urbanity perspective, in turn, must be able to deal with the repleteness of sectorspecific tools and approaches in the face of a horizontal and integrative policy goal, such as pursuing sustainability. This would not necessarily contradict the smart city perspective. 
However, it would look beyond technically elegant solutions reached via the smart city tools and emphasize the need for creating meaningful assemblages of components that have the potential to turn out effective proxies for sustainable development. For instance, the PALM, in addition to its role as a tool for managing large-scale strategic projects, can at best be a truly integrative and truly smart artefact. Yet such a process of becoming smart would require the smart use of smart tools from the entire assemblage of actors involved in it - and a universal recognition that smartness, first and foremost, must be required from people and their organizations. It makes perfect sense to conclude that public management and public managers have an important role in facilitating this process, particularly as becoming 'smart about city' (cf. Hajer 2014) not only relies heavily on data created by public actors but is a major resource for them to use.

As our empirical findings revealed, the PALM is still in the making. As a tool, it did not come out of thin air but must be understood as an iteration, an artefact with a history of prior modifications for best reaching its targeted outcomes. The outcome discussed in this paper was sustainable urban development - or rather a proxy for it. Conversely, the PALM can be seen as an example of a ubiquitous smart city tool for making, iteration after iteration, a better proxy. As for the tool's further elaborations, it might be worthwhile to develop it with an eye on the cognitive and experiential understanding of the actual use of the city, as an environment, a physical platform and a cityscape that its dwellers live by, day in and day out. That would be a step away from the hyper-engineered smart city aspirations and towards the kind of smart and sustainable urbanity that the legendary proponents of better cities, starting from Jane Jacobs (1961), would undoubtedly have appreciated. 


\section{References}

Alfeld, L. E. 1995. Urban dynamics: the first fifty years. System Dynamics Review 11 (3): 199-217.

Beauregard, R. A. 2012. Planning with things. Journal of Planning Education and Research 32 (2): 182-190.

Beauregard, R. A. 2015. Planning matter. Acting with things. Chicago, IL: University of Chicago Press. Beauregard, R. A. 2018a. Cities in the urban age. A dissent. Chicago, IL: University of Chicago Press.

Beauregard, R. A. 2018b. The entanglements of uncertainty. Journal of planning education and research. DOI: 10.1177/0739456X18783038

Berke, P.R. 2002. Does Sustainable Development Offer a New Direction for Planning? Challenges for the Twenty-First Century. Journal of Planning Literature, 17 (1): 21-36.

Blanco, H., and Mazmanian, D. A. 2014. The sustainable city: introduction and overview. In Mazmanian, D. A., and Blanco, H. (eds.) Elgar Companion to Sustainable Cities. Strategies, Methods and Outlook. Edward Elgar.

Brynjolfsson, E., and McAfee, A. 2016. The second machine age. Work, progress and prosperity in a time of brilliant technologies. New York, NY: W.W. Norton.

Carpo, M. 2017. The second digital turn. Design beyond intelligence. Writing Architecture Series. Cambridge, MA: The MIT Press.

Castelnovo, W., and Sorrentino, M. 2018. Engaging with complexity in a public programme implementation. Public Management Review, 20 (7): 1013-1031.

Castro, F. G., Kellison, J. K., Boyd, S. J., and Kopak, A. 2010. A methodology for conducting integrative mixed methods research and data analyses. Journal of Mixed Methods Research 4 (4): 342-360.

Center for Transit-Oriented Development. 2009. Mixed-income housing near transit. Increasing affordability with location efficiency. TOD 201. Washington, D.C.: Federal Transit Administration.

Chakrabarti, V. 2013. A country of cities. Manifesto for an urban America. New York, NY: Metropolis.

City of Tampere. 2018. Smart Tampere. https://www.tampere.fi/en/smart-tampere.html, accessed October 282018.

Cohen, S. 2018. The sustainable city. New York, NY: Columbia University Press.

Duany, A. 2013. A general theory of sustainable urbanism. In Landscape urbanism and its discontents. Dissimulating the sustainable city, edited by A. Duany and E. Talen, 115-123. Gabriola Island BC: New Society Publishers.

Duany, A., and Talen, E. (eds.) 2013. Landscape urbanism and its discontents. Dissimulating the sustainable city. Gabriola Island BC: New Society Publishers.

Finco, A., and Nijkamp, P. 2001. Pathways to urban sustainability. Journal of Economic Policy \& Planning 3 (4): 289-302.

Flyvbjerg, B., Bruzelius, N., and Rothengatter, W. 2003. Megaprojects and risk. An anatomy of ambition. Cambridge: Cambridge University Press.

Forrester, J. W. 1970. Systems Analysis as a Tool for Urban Planning. IEEE Transactions on Systems Science and Cybernetics, 6 (4): 258-265.

Gardner, G., Prugh, T. \& Renner, M. 2016. Can a city be sustainable? State of the World. The Worldwatch Institute. Washinton, D.C.: Island Press.

Graeber, D. 2015. The utopia of rules. On technology, stupidity and the secret joys of bureaucracy. Brooklyn, NY: Melville House.

Hajer, M. 2014. On being smart about cities. In Smart about Cities. Visualising the Challenge for 21st Century Urbanism, edited by M. Hajer and T. Dassen, 9-43. Rotterdam: nai010 publishers/PBL publishers.

Hajer, M, Dassen, T. (eds.) 2014. Smart about Cities. Visualising the Challenge for 21st Century Urbanism. Rotterdam: nai010 publishers/PBL publishers. 
Hamblyn, R. 2009. Terra. Tales of the Earth. Four events that changed the world. London: Macmillan/Picador.

Hoornweg, D. 2016. Cities and Sustainability. A new approach. Routledge.

Hoornweg, D., Sugar, L., and Trejos Gómez, C. L. 2011. Cities and greenhouse gas emissions: moving forward. Environment and Urbanization 23 (1): 207-227.

Jacobs, J. 1961. The death and life of great American cities. New York, NY: Vintage.

Johanson, J-E., and Vakkuri, J. 2017. Governing Hybrid Organisations - Exploring Diversity of Institutional Life. London/New York: Routledge.

Kadanoff, L. P. 1971. From simulation model to public policy: An examination of Forrester's "Urban Dynamics". Simulation 16: 261-268.

Karppi, I., and Vakkuri J. 2019. Organising complexity: Creating boundary objects for sustainable urban development. In Leading change in a complex world. Transdisciplinary perspectives, edited by A. Kangas, J. Kujala, A. Heikkinen, A. Lönnqvist, H. Laihonen, and J. Bethwaite, 45-64. Tampere: Tampere University Press.

Katz, B., and Wagner, J. 2014. The Rise of Innovation Districts: A New Geography of Innovation in America. Metropolitan Policy Program. Washington, DC: Brookings Institution.

Keenan, J. M. 2014. Adaptive capacity of commercial real estate firms to climate change in NYC. The Center for Urban Real Estate at Columbia University. GSAPP Books. New York, NY: CURE.

Keenan, J., and Chakrabarti, V. 2013. NYC 2040: housing the next one million New Yorkers. GSAPP Books. New York, NY: CURE.

Latour, B. 1994. Pragmatogonies. A mythical account of how humans and nonhumans swap properties. American Behavioral Scientist, 37 (6): 791-808.

Latour, B. 2014. Agency at the time of the Anthropocene. New Literary History, 45: 5-6.

Lieto, L. 2017. How material objects become urban things? City, 21 (5): 568-579.

Lyster, C. 2016. Learning from logistics. How networks change our cities. Basel: Birkhäuser.

MacKaye, B. 1968. From geography to geotechnics. Edited by P. T. Bryant. Urbana, IL: University of Illinois Press.

Mattern, S. 2015. Mission control: a history of the urban dashboard. Places Journal, March 2015. Accessed 20 Oct 2018. https://doi.org/10.22269/150309.

McFarlane, C., and Söderström, O. 2017. On alternative smart cities. City, 21 (3-4): 312-328

McPhearson, T., Pickett, S. T. A., Grimm, N. B., Niemelä, J., Alberti, M., Elmqvist, T., Weber, C., Haase, D., Breuste, J., and Quershi, S. 2016. Advancing urban ecology toward a science of cities. BioScience, 66 (3): 189-212.

Meadowcroft, J. 1999. Planning for sustainable development: what can be learned from the critics. In Planning sustainability, edited by M. Kenny and J. Meadowcroft, 12-38. London: Routledge.

Meadowcroft, J. 2007. Who is in charge here? Governance for sustainable development in a complex world. Journal of Environmental Policy \& Planning 9 (3-4): 299-314.

Medina, E. 2006. Designing freedom, regulating a nation: socialist cybernetics in Allende's Chile. Journal of Latin America Studies 38 (3): 571-606-

Meijer, A., and Bolivar, M. P. R. 2016. Governing the smart city: a review of the literature on smart urban governance. International Review of Administrative Sciences 82 (2): 392-408.

Mergel, I. 2018. Open innovation in the public sector: drivers and barriers for the adoption of Challenge.gov. Public Management Review, 20 (5): 726-745.

Mumford, L. 1949. Kaupunkikulttuuri. Original: The culture of cities, 1938. Porvoo: WSOY.

Nam, T., and Pardo, T. A. 2011. Smart city as urban innovation: focusing on management, policy and context. Paper presented at ICEGOV2011, September 26-28, 2011. Tallinn.

Owen, D. 2010. Green metropolis. Why living smaller, living closer and driving less are the keys to sustainability. New York, NY: Penguin/Riverhead Books. 
Paans, O.,and Pasel, R. 2014. Situational urbanism. Directing post-war urbanity. Berlin: Jovis.

Pelenc, J., and Ballet, J. 2015. Strong sustainability, critical natural capital and the capability approach. Ecological Economics, 112: 36-44.

Portney, K. E. 2013. Taking Sustainable Cities Seriously. Economic Development, the Environment, and Quality of Life in American Cities. Second Edition. The MIT Press.

Ratti, C., and Belleri, D. 2017. Sense and the City. Towards a new digital common. In Imminent commons: urban questions for the near future. Seoul biennale of architecture and urbanism 2017, edited by A. Zaera-Polo and Hyungmin Pai, 180-191. New York, NY: Actar Publishers.

Ratti C., and Claudel, M. 2016. The city of tomorrow: sensors, networks, hackers, and the future of urban life. New Haven, CT: Yale University Press.

Renne, J. L. 2009. From transit-adjacent to transit-oriented development. Local Environment, 14 (1): 1-15.

Revellino, S., and Mouritsen, J. 2015. Accounting as an engine: The performativity of calculative practices and the dynamics of innovation. Management Accounting Research, 28: 31-49.

Rosati, U., and Conti, S. 2016. What is a smart city project? An urban model or a corporate business plan? Procedia - Social and Behavioral Sciences 222 (2016): 968-973.

Rottle, N., and Yocom, K. 2010. Ecological Design. Basics Landscape Architecture Series. Lausanne: AVA.

Rumpfhuber, A., Klein, M., and Kolmayr, G. 2012. Almost all right: Vienna's social housing provision. Architectural Design, 112 (04): 88-93.

Sorkin, M. 2013. Rumble in the Urban Jungle. A recent book by New Urbanist authors revives an old battle with Landscape Urbanism. Architectural Record, August 2013. https://www.architecturalrecord.com/articles/6220-rumble-in-the-urban-jungle?

Speck, J. 2012. The walkable city. How downtown can save America, one step at a time. New York, NY: Farrar, Straus and Giroux.

Steiner, F. 2011. Landscape ecological urbanism: origins and trajectories. Landscape and Urban Planning 100: 333-337.

Sterling, B. 2018. Stop saying 'smart cities'. Digital stardust won't magically make future cities more affordable or resilient. The Atlantic Feb 12, 2018.

https://www.theatlantic.com/technology/archive/2018/02/stupid-cities/553052/

Stern, I. 2010. The New York City watershed: a community-based approach. In Intractable democracy. Fifty years of community-based planning, edited by A. Venkataraman, 171-176. Programs for Sustainable Planning and Development, School of Architecture. New York, NY: Pratt Institute.

Stern, N. 2010. A blueprint for a safer planet. How we can save the world and create prosperity. London: Vintage.

Submission by Latvia and the European Commission on behalf of the European Union and its Member States. 2015. Intended nationally determined contribution of the EU and its Member States. Riga.

Talen, E. 2011. Sprawl retrofit: sustainable urban form in unsustainable places. Environment and Planning B: Planning and Design, 38: 952-978.

Townsend, A. M. 2014. Smart cities: Big data, civic hackers, and the quest for a New Utopia. New York, NY: W. W. Norton.

Vakkuri, J. 2010. Struggling with ambiguity: Public managers as users of NPM-oriented management instruments. Public Administration, 88 (4): 999-1024.

Vakkuri, J., Karppi, I., and Sankala, I. 2016. Päätöksenteon sudenkuopat: julkisen talouden tuloksellisuus ja yhdyskuntarakenteen kestävyys. In Strateginen eheyttäminen kaupunkiseuduilla. Näkökulmia kestävän maankäytön ja julkisen talouden kysymyksiin, edited by S. Puustinen, R. 
Mäntysalo and I. Karppi, 45-61. Valtioneuvoston selvitys- ja tutkimustoiminnan julkaisusarja 4/2016. Helsinki.

Van Dooren W., Bouckaert G. and Halligan J. 2015. Performance Management in the Public Sector. Oxford: Routledge.

Van Dorp, E.-J. 2018. Trapped in the hierarchy: The craft of Dutch city managers. Public Management Review, 20 (8): 1228-1245.

Vanolo, A. 2014. Smartmentality: The Smart City as Disciplinary Strategy. Urban Studies, 51: 883-898. Wartiainen, K. 1995. Ekologinen kone ja arkkitehtuuri. In Ekopolis. Ekologisen kaupungin juuria etsimässä, edited by K. Lapintie, B. Koskiaho, T. Ikonen and U. Tiilikainen, 181-207. Helsinki: Gaudeamus.

Vosselman, E. 2014. The 'performativity thesis' and its critics: Towards a relational ontology of management accounting. Accounting and Business Research, 44 (2): 181-203.

Zeemering, E. S. 2018. Sustainability management, strategy and reform in local government. Public Management Review, 20 (1): 136-153.

Appendix: Interviews

\begin{tabular}{|llll|}
\hline Date & Informants & Method, outputs & Duration \\
\hline Apr. 16, 2015 & $\begin{array}{l}\text { 4; senior executives, division } \\
\text { heads }\end{array}$ & Group interview, recording/transcript & 72 min \\
Mar. 6, 2017 & $\begin{array}{l}\text { 6; division heads, senior managers, } \\
\text { strategy and other specialists } \\
\text { 3; line managers and a specialist } \\
\text { planner }\end{array}$ & Group interview, recording/transcript & 77 min \\
Dec. 8, 2017 & Group interview, recording/transcript & $91 \mathrm{~min}$ \\
\hline
\end{tabular}



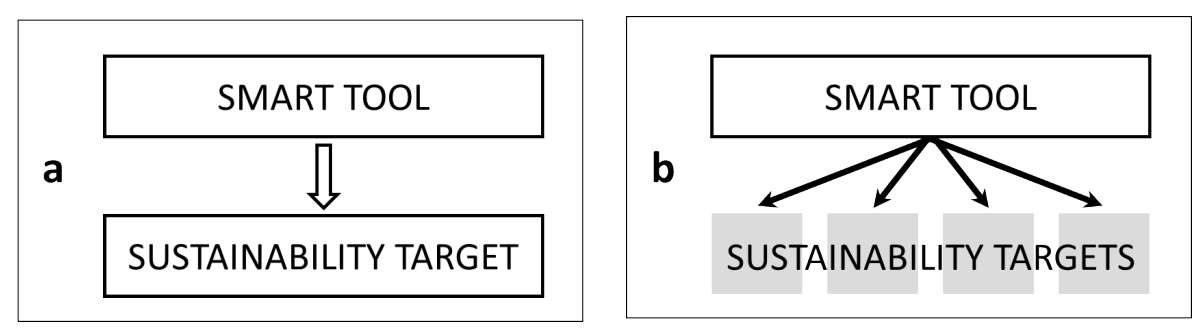

Figure 1. Sustainability proxy in the making: from one grand target to a set of sub-targets reflecting the administrative division of labour. 


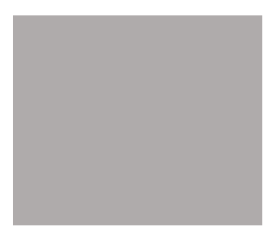

A. Original

sustainability target

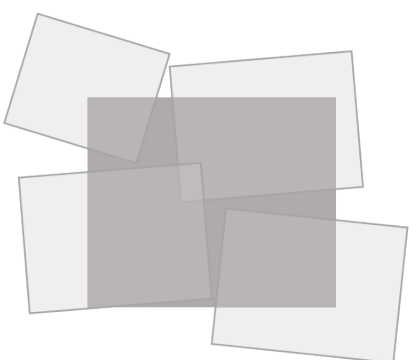

B. Sustainability proxies that seek to capture the original target

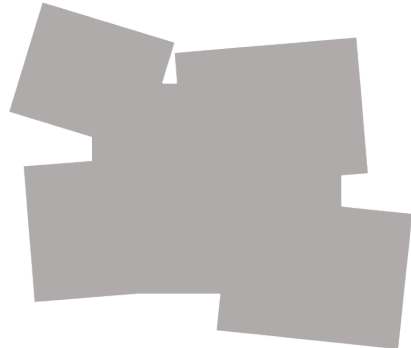

C. Sustainability target mutated through proxies

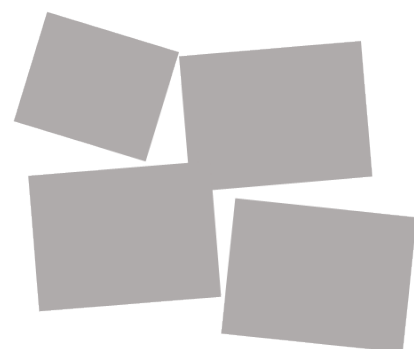

D. 'Acquired sustainability' measured through proxies

Figure 2. Sustainability proxies in urban policy-making 